\title{
Observation, Conviction, Passion: Personal Situated Professional Concerns in Applied Linguistics
}

\author{
Yazid Basthomi \\ Jurusan Sastra Inggris, Fakultas Sastra, Universitas Negeri Malang, Indonesia \\ Email: ybasthomi@um.ac.id
}

\begin{abstract}
Taking a self-reflexive approach, this paper presents my own narratives as a professionalpractitioner in the area of applied linguistics within the educational context of Indonesia. Through these narratives, I present selected concerns I feel compelling for the purpose of self-recast of my understanding of some issues to direct my future professional trajectories and of manifesting my obligation to share the understanding for the benefit of thinking-narrating human beings. Self-herocising this paper may sound, I resort to perplexing challenges I face as a professional affiliated with an institution situated in a developing country. I would also take the seemingly self-herocizing casting of the paper as a self- and communalconsolation.
\end{abstract}

Index Terms — self-reflexive, self-narrative, developing country, Indonesia

\section{INTRODUCTION}

"You make an observation and you have an obligation", says M. K. Asante on various occasions. This article delineates my observations as a practitioner in the realm of applied linguistics. These observations have built up my conviction which sustains my passion in providing services in the area. Building on all these, I am going to speak of my concerns showing contingent, tentative manifestations of my obligations. Taking a personal approach, this piece of writing is a fulfilling response to Nelson's (2011) remark that

... practitioners who wish to investigate or reflect on aspects of their own teaching-particularly aspects that are potentially contentious - do not necessarily have access to the formal mechanisms that provide authorisation or support for research (p. 470).

As such, celebrating my agency, this paper enables me to point out that a turn taken to reflexive auto-narrative study promises a way to extend the reach of the course-line cast by the narrative turn (see e.g., McLeod, 2006; Gimenez, 2010).

Recently, one of the characteristics of my academic undertaking has taken the auto-reflexive approach. However, I have not made clear the connections of my previous projects to narrative approach. Against this backdrop, I'd take this opportunity to attempt the clear links of my recast of self-reflection to narrative approach wherein I am particularly exercising the auto-narrative writing of my concerns in the realm of applied linguistics or English language teaching within the educational context of Indonesia.

Oftentimes, as reading research reports, be they in the forms of dissertation/thesis, research articles published in scholarly journals or other forms, I have an impression that research in my area, applied linguistics, specifically, and social sciences in general, tends to deal with people other than the researchers themselves. So, despite the lapse of some decades subsequent to the so-called narrative turn, research tradition in the social sciences and humanities are still predominantly about the narratives of the people other than the researchers themselves (see, e.g., Helsig, 2010; Fischer and Goblirsch, 2006; Schnee, 2009; Tardy, 2005; Lapadat, 2004). When TESOL Quarterly, one of the influential journals in my field, published a special collection of articles on narrative research, I was both joyous and upset. On the one hand, I was happy because the narratives of the unheard became heard (Denshire, 2010; Lapadat, 2004), which allows for more intensive and extensive human communication and understanding. On the other hand, I was disconcerted to learn that the collection does not really allow for the thrusting of the agency of the researcher with his/her own narratives. What we can read is mainly a bunch of articles reporting the narratives of the research participants. I am avoiding the term "research subjects", for this term to me blurs the embedded objectification that exists in research involving other people as sources of the data even when they are referred to as "subjects" which seems to lay "objectification" diminutive.

Reading an article reporting on the professional life of an English teacher providing his services in a peripheral area in Sri Lanka (Hayes, 2010), my feeling was flooded with palpitation. Illuminating as it is, I was stirred by my compelling expectation that the narratives had been presented by the subject himself. Even though one may relegate to the notion of insider's view, he/she somehow uses his/her own perception and framing on the insider's view. Even 
when one is successful to secure confirmation from the research participants about the narratives being reported, he/she is exercising his/her own agency in the presentation of other people's narratives.

Similarly, Tardy brought to my attention her article "It's like a story": Rhetorical knowledge development in advanced academic literacy published in English for Specific Purposes (Tardy, 2005, pp. 325-338), as she was giving a talk at the English Language Institute (ELI), University of Michigan-Ann Arbor (November 2005). The article and the talk knocked on my conscience as to ask "Had her research participants spoken directly about their narratives on the issue raised, would they really expressed exactly the same thing?" Another question was, "If Tardy could select the narratives of her two research participants, can't I select my own narratives, for I may play the role of a research participant myself. The same questions popped up in mind as I read Schnee's (2009) article "Writing the personal as research" engaging her students as her research participants in writing their personal educational journeys, Lapadat's (2004) "Autobiographical memories of early language and literacy development" involving nine women research participants and other research employing this kind of approach (see also Fischer and Goblirsch, 2006). When I take the dual role of the researcher and the researched (without submitting to other researchers) concomitantly, I can work about my narratives of my own selection bearing my own agency as a thinking subject.

One may observe that the above is an index of envious academic resentfulness. Acknowledging the merit of such a potential remark, I would take it to a fruitful direction whereby I would argue that both Tardy's research methodology, which is typical in a number of academic ventures (see e.g., Rogers, 2011; Fischer and Goblirsch, 2006, Schnee, 2009) and the auto-ethnographic methodology or self-reflexive (e.g., Denshire, 2010; Fenge, 2010) which I am taking, share a characteristic in common: both value and resort to narratives of the research participants as the sources of the researchers' understanding thus their findings. What is different, probably, is that there seems to be "objectivity" in research epitomized by Tardy (2005) aforementioned, for it does not directly deal with the researchers themselves.

Examining closely, we, however, would find that both, to a great extent, share some kinds of subjectivity of the researchers. The researchers are bound to relegate to their subjective understanding as they embark on the plane of analysis of the research participants' narratives which, in themselves, have been selected by the research participants. Probably, an epitome of research involving other people yet judiciously acknowledging and making use of the researcher's own subjectivity in the joint construction of selected-narratives is that by Baynham (2000). This notion of selected-narratives in fact poses no different nature from those narratives selected by the researchers themselves in autoethnographic study as exemplified by Denshire (2010) and Fenge (2010). Since applied linguistics does not have immediate needs for "truth" as conceptualized in hard sciences, narratives (including auto-narratives) are reliable sources for human engagement, as Rogers (2011) has shrewdly pointed out:

Narratives do not trade in facts, solve problems or attempt to tell "truths"; instead they are satisfying to the degree that they abide by standards of coherence, fidelity, appropriateness and timeliness: they engage with contested issues in human life in believable ways [emphasis original] (p. 9).

Both, the seemingly objectively approached narratives (of other people) and auto-narratives relate to informed opinions as the need to report the study arises. And informed opinions have to do with rhetoric whose relationship with the working of science has been acknowledged to be inseparable (Golden, Berquist, and Coleman, 1984).

It is true that for the purpose of conceptualization we may differentiate between science and rhetoric in that 1) science deals with "facts" and rhetoric with "informed opinions", 2) the goal in science is to "describe the world" and rhetoric to "regenerate" the world, 3) science propounds general truths in the form of law-like statements, whereas rhetoric applies socially approved values to specific cases requiring choice or decision, and 4) the man of science can produce a discourse expressive or generative of knowledge without engaging another mind, but the man of rhetoric is so much concerned with the presence of the audience (Golden et al., 1984, p. 455). But, there has, recently, been a shift that science is no longer a business of individual scientists where scientific claim is only verified by individual scientists and where the external world is as the scientific claim describes it; rather, science is nowadays a social enterprise. This bears a consequence that science has to do with "cooperation" and, thus, "communication" among a number of people (Golden et al., 1984). Referring to Ziman's observation, Golden et al., (1984, p. 456) believe that scientists are now concerned more with "acceptance" than "truths"; science is a matter of "consensus". In this situation, inter-subjective validity emanating from auto-narratives has potential of acceptance. In this line, in reference to Kuhn, Golden et al., (1984) see scientific endeavors as a matter of coping with anomalies which necessitate the scientists to be able to convince others; so, again, acceptance is the eventuality.

As a piece of auto-narrative study, this article takes the same spirit of those by Knee (1999), Papp (1999), and Orbán (1999). While Knee and Papp spell out narratives selected from their experiences in teaching in settings with cultures than their own, Orbán refers to her narratives as a student. Knee and Papp thus take a similar role to that of Tardy, yet their role is different in that they use themselves as research participants of their own research. Whilst Tardy engaged others as participants of her research, Knee and Papp selected their own narratives as source of their research data. While Tardy has the power to select the narratives of her research participants, Orbán has the power to organize her own narratives. So, basically, both have a similar subjective-qualitative approach. In this line, the present article shares similar features of research methodology to that of Orbán.

This being said, the present article shares some similarities with the (auto)biographic narratives edited by Belcher and Connor (2001) in the volume-length of Reflections on Multiliterate Lives. However, the present article has to do with 
the narratives of myself residing in a periphery, geographically (and academically). The narratives presented in the anthology by Belcher and Connor are of and by those with well-celebrated academic stature, for instance, Nils Erik Enkvist, A. Suresh Canagarajah, and Andrew W. Cohen. Again, I would take positively this opportunity to claim that the present article addresses the under-use auto-narrative approach to study in applied linguistics and to thrust my voice as an Indonesian practitioner in applied linguistics.

Probably it is true that some research participants do not have the capability to express their narratives in an engaging way deserving wide readership. Conversely, some research participants possibly have the joy in expressing their narratives to other people or researchers; so, the narratives they tell may constitute the purposeful unpacking of their identity. Despite some debates around identity enactment in narrative study, what is immediately promising is that narrative research, including for sure auto-narratives, allows for the unheard voices to be heard (Denshire, 2010), or small stories to be heard (Lapadat, 2004). Of course, in the practical professional context, it is too luxurious to have backward orientated narratives for the sheer enjoyment of the sentimental bearings; rather, the very act of the present unpacking of the narratives and the effected future actions are the meanings worked about (Bamberg, 2006).

I should note here that some points of my narratives sprawling in the following have appeared somewhere; however, narratives are dynamic and their meanings may be different invoking different nuances in different moments enriching our understanding, for, as Rogers (2011) astutely puts it,

'...narrative lens involves dynamism in at least these ways: the shape and details of the experiences change in memory and then change again in the process of writing, for words come with echoes and restrictions; writers themselves change, so that they are no longer the same as when the event occurred; and how writers understand experience is constantly developing, so that the meaning of experience is unending palimpsest ( p. 2)

Even though the dynamism of narratives as products of discourse may suggest exuberances and deficiencies simultaneously (Becker, 1996), carrying over products of subject(ive)-object(ive) interaction (Rogers, 2011), as readers feel a hold of coherence, for coherence is external to texts (Renkema, 1993), my auto-narrative writing fulfills its purpose: reshaping my own understanding and enriching the understanding of the readers through the coherence they cast onto my narratives.

\section{A. Concern \# 1: Rhetorical Awareness}

The first narratives standing out in my memories took place when I started my graduate career in an Australian university (see Basthomi, 2006). It started as a perplexity hampering me as I had to prepare a Master's language project proposal right from the outset as I commenced the Master's program in the first semester (out of the two semesters). I felt the need to consult sample research proposal to grapple for ideas of what to include in (and to exclude from) the proposal. Inclusion and exclusion of materials in a research proposal refer to the interweaving of both content and rhetoric. This nascent awareness then developed further through advisement processes the crux of which has to do with attempts to ascertain that a research proposal should rhetorically demonstrate how my research topic is different from and similar to that of other researchers, how the research method I selected was distinctly relate to that of other researchers in the relevant area, and how the theoretical stance I took linked shrewdly to others as to show its distinctiveness of some sort.

Such was the essence of the narratives of constitutive of my rhetorical awareness with regard to advisement processes I underwent. These selected tentative narratives were later affirmed through collegial discussions with a fellow friend pressed for time with Ph.D. proposal submission deadline. Whilst anxiously looking forward to decision on my Master's project, an Indonesian fellow brought me some versions of drafts of Ph.D. proposal altogether with comments from her supervisor. Quickly browsing the drafts, my tentative narratives as noted above stood out in my conscience as to say that my friend was faced with similar problems to what I had been confronted with. Referring to such narrative sources, I could capitalize myself with the three issues as guiding questions for my fellow friend work out her proposal. As she had the necessary materials of the content, what was left was the wrapping of the contents. In other words, she was mainly confronted with rhetorical problems which crystalized in the three key issues abovementioned as expected by the discourse community represented by her supervisor (Swales, 1990, 2004; Askehave and Swales, 2001).

Successful with my capitalization through my narratives, I developed a seed of bravery to dream of embarking on a doctoral degree. My narratives have led me to a conviction that producing academic writing, including necessarily the taxing doctoral thesis, is all about rhetoric. This rhetorical awareness is my key to open the door of my doctoral degree.

\section{B. Concern \# 2: Research Space}

The first narratives aforementioned did function as my leverage to embark on a doctoral program. In fact, the topic of my doctoral thesis was on rhetoric, i.e., the rhetoric of research article (RA) introductions written in English by Indonesians. I should note here that my first narratives went harmoniously with my reading of Flowerdew's (2001) research findings regarding international journal editors' views about the submitted manuscripts by non-native English speakers (NNS). Among other things, the editors' views are centered around the issue of rhetoric, that is, the tendency of the NNS to fall short of attempt to carve out research niche, a term which goes to Swales (1990) CARS model.

Done with my doctoral thesis, I started to develop a sort of "suspicion", that is, what rhetorically manifests in research articles by Indonesian writers may relegate to the inculcating practices in graduate studies, particularly, in the writing of candidacy. In this regard, I saw the logic to pay heed to Indonesian doctoral prospectuses. Since work in the 
area of applied linguistics, particularly, English language teaching, I analyzed prospectuses written in English by Indonesian doctoral students of ELT. This undertaking has yielded some points of understanding (Basthomi, 2009).

Regardless of the length of the background of the prospectuses, the texts tend strongly to be dense with review of concepts. To cite an example, analyzing the background a text of doctoral prospectus titled "Genre Analysis of International Conference Paper Abstracts" which runs on 34 paragraphs, I found that, out of the 34 paragraphs, 21 paragraphs relate to review of concepts. It is true that Swales" (1990) CARS model makes a mention of a "review". To my understanding, however, Swales (1990) refers the review to that of items of previous research. This insinuates that in the attempt to "establish a territory" thus working on a research space in a research proposal, one is required to link his/her research to the web of research in the relevant area (Basthomi, 2009). Let me quote an excerpt that I have used (Basthomi, 2009). The excerpt has been taken verbatim from a doctoral prospectus titled "Learning Strategies across Cultures of EFL Learners Residing in Nusa Tenggara Timur (NTT) Province".

Up to this point, knowing more of what learning strategies are all about is important. Learning strategies refer to any specific procedures, ways, techniques or tactics learners use in learning a language, especially in learning English. It is believed that every EFL learner adopts specific learning strategies. Every EFL learner can use different learning strategies showing his or her way of learning. For example, an EFL learner, in making meaning of an unfamiliar word in an English reading passage, may adopt consulting dictionary strategy and another may use inferring from context strategy.

Excerpt 1 indicates that the proposal writer is cognizant of the main variable of her/his proposed research project. This awareness, however, does not lead the writer to the need to problematize issues around the variable based on previous empirical studies; rather, he/she relegates to concepts around the variable.

The above issue indicates that the doctoral students tend to place a preference on "positive justification" which is considered optional in Swales' (2004) CARS Model and put aside the other two steps of "indicating a gap" and "adding to what is known". To put it brief, Indonesian doctoral students tend to have problems in working about research space.

\section{Concern \# 3: Gate Keeping}

One point in the collage of my narratives is the urge, I felt, to relate my own rhetorical awareness and the notion of the Indonesian writers' (and also doctoral students') problems to deal with research space. The inter-textual link of this concern is my focused interviews with few journal editors/reviewers who function as academic discourse community expert members who assumed the responsibilities of gate-keeping the academic discourse (Swales, 1990). One of the important results of the interviews (Basthomi, 2007) refers to the fact that Indonesian journal editors/reviewers had not held orientation towards international readership. The editors/reviewers were pessimistic about international orientation. This pessimism has been attributed to two main reasons: the fact that their journals do not employ English native editor(s) and the parochiality of the manuscripts they receive.

Based on the above points of findings, it can be safely assumed that the editors/reviewers had not led the manuscript contributors to have the international readership orientation either. As such, it is understandable why the RAs that I have analyzed tend not to show indication of attempts to work about research space as a much expected property of manuscripts published in international journals (suggesting the use of English as the communicative medium) as indicated by Swales (1990, 2004).

The above points also suggest that claims that Indonesian students (suggesting, in turn, the graduates) of EFL tend to be able to produce the acceptable academic essays (see, e.g., Latief, 1990; Harjanto, 1999) do not readily guarantee that they would easily succeed to write research articles or doctoral thesis proposals. Kartika (1997) is right in her observation that writing in the same genre of articles notwithstanding, Indonesian writers of English texts and native English writers tend to draw on discourse conventions or norms, potentially different from those practiced in international publications.

Consequently, in view of the necessity for Indonesian academics to actively make contributions to global academic discourse which suggests the use of English, Indonesian academic gatekeepers-encompassing journal editors/reviewers and thesis supervisors-need to observe the potential expectations of the gatekeepers of the international discourse community as have shrewdly and fruitfully been documented, for instance, by Swales (1990; 2004) and Flowerdew (2001). Even so, this pragmatic arising need should be viewed with caution. As genre is dynamic (Berkenkotter and Huckin, 1995; Askehave and Swales, 2001), rhetorical expectations of International academic discourse gate-keepers are also bound to be change over time. Consequently, any observations of the rhetorical orientations and expectations should be put in perspective.

\section{Concern \# 4: News Value}

Altogether and inextricably the pieces of my narratives inter-textually link to other narratives one of which is Berkenkotter and Huckin's (1995) news value of article publication. In my conviction then, the notion of the difficulties Indonesian writers and doctoral students face in carving out research spaces in their research articles and doctoral thesis prospectuses, respectively, shares some affinity with the difficulties, particularly of my students, to present research proposals bearing news value. Therefore, as a lecturer, I have been informed by the ensuing conviction that I need to raise rhetorical awareness encompassing students' understanding of the issues of research space and news value. All 
this is what has characterized my teaching principle in handling a course on Thesis Proposal Seminar, both undergraduate and graduate.

My personal observations have demonstrated that students who come to terms with the issue of research space and write accordingly in their research proposals tend to be successful in convincing their thesis supervisors and examiners. They also tend to meet the expectation of news values as they are successful to work out research spaces (not the reverse). My conviction and thus teaching principle have also been evident. With an experimental guise in mind, once I asked an undergraduate student whom I considered successful in working out a research space in her thesis to make a presentation before graduate students who were attending my graduate Thesis Proposal Seminar. On the one hand, I meant this as a rehearsal for the undergraduate student prior to her viva, and on the other hand, I intended to see if undergraduate and graduate levels really matters when research spaces (thus news values) were worked out successfully.

What I personally saw was that the 15 or so graduate students attending the seminar were speechless, for, as I predicted, all their expectations seemed to be met by this undergraduate presenter. Or, even probably, some kinds of exuberance were there that the undergraduate presenter had more than expected by the graduate students. The picture residing in my memory was that the graduate students just kept smiling as the 20 minute or so presentation was over and the only one question emerging was "Are you a graduate student?" This question was warranted, for, purposefully, I did not reveal the academic identity of the undergraduate presenter prior to the presentation. This was to avoid possible ensuing disregards on the part of the graduate students and also to avoid a potential impression that I was belittling the graduate students by inviting my undergraduate advisee to make a presentation before them. The narrative did not stop there as yet, for in the viva voce of the undergraduate student, one examiner gave her the score of $96 \%$ and the other granted her $100 \%$.

\section{E. Concern \# 5: Perplexities}

One might have an impression that the foregoing narratives, particularly the testimonial sample narratives, sound self-heroicizing (Underwood, 2011) and liable to what Nelson (2011) characterizes as "self-consciously clever" (p. 465) Acknowledging such possible exuberances of the narratives (Becker, 1996), I would turn to another side where the more massive voices have been residing, for cream is bound to be less than the rest. What I am trying to say is that alongside the above narrative odyssey, I have observed students and colleagues, through both first hand observations and second hand (through text analyses), including myself obviously, grapple with rhetorical issues in writing their articles and research proposals. And as I use my narratives as sources for discussion with students and colleagues, we all, as residents situated in a developing country, feel that we are disadvantaged and thus questioning the immediate pertinent issues as "How can we carve out research spaces if we cannot avail ourselves of recent publications in the field?", "How can we write articles or research proposals with news value if we fail to carve out research niches due to failure to get access to recent publications in the area?", and "How can we satisfy the expectations of international discourse community gatekeepers if we cannot carve out research spaces in our research articles when aspiration to publish compel in mind?" etc.

As an attempt to answer those typical questions, some have turned to readily available online sources. This strategy to some extent proves to be fruitful; but, to some other extent, perpetuates the second-classness, for the cream recent publications remain the possession of big shots the access to which is surely with costs. This is the biggest challenge charging individuals affiliated with institutions underfinanced in a developing country after some kinds of sharing of narratives have done the job of bringing to us some light.

Such a situation also seems attributable to another issue. Let me take a specific case of my department: English Department. It is not uncommon that all the faculty members experience undertaking post-baccalaureate studies, be they post graduate diploma, Master's or Ph.D., abroad, particularly in English speaking countries. However, to my understanding, quite few of us are able to maintain research and publications for international readership. We tend to spend our labor in the form of providing inward services, meaning that our expertise is mainly expedited for our fellow countrymen. Virtuous as it is, for we do care for our immediate-significant others, but my conviction is that the hardship to get access to recent publications in the mainstream media (journals, monographs, research reports and the like) is the main factor attributable to the difficulties in carving out research spaces and crafting scholarly writing with news value, thus, potential for international publication.

Against the backdrop of such a situation, my consolation along my narratives has been trying to maximally make use of whatever available as exemplified by my undergraduate student aforementioned. If we can do well with limited resources, we actually can excel when our situation is as good as other people living in better off countries with better off facilities and access to quality first class publications.

\section{CONTINGENT CONCLUSION}

The instantiation of this reflexive writing whereby I revisit and recast my narratives through situated framing and reframing (Fenge, 2010) has allowed me to vent out and off the load of my obligation implicated by my observations on which my conviction has been continually built (and also refurbished). This undertaking has taken and dropped me onto some perplexities through which balanced equilibrium is continuously sought, which helps sustain my passion in the profession. Inward in nature, this self-oriented consolation I believe has the potential for shared-identification by others 
as the writing reaches readers. When this expectation is met, the casting of my obligation is tentatively done, for along the process of completing an obligation, other observations are bound to be made in our humanly perceptions and cognition and, therefore, other narratives (and/of) other obligations are awaiting. There we go with "unending palimpsest" (Rogers, 2011, p. 2) of Asante's dialectic observation-obligation: the passion.

\section{ACKNOWLEDGEMENT}

The writing of this article was carried out during an academic retreat in the U.S. with the PAR 2011 fellowship under the auspices of Direktorat Pendidik dan Tenaga Kependidikan, Ditjen DIKTI, Kementerian Pendidikan Nasional, Republik Indonesia.

\section{REFERENCES}

[1] Askehave, I. and J. Swales. (2001). Genre identification and communicative purpose: A problem and a possible solution. Applied Linguistics 22 (2), 195-212.

[2] Bamberg, M. (2006). Stories: Big or small, Why do we care? Narrative Inquiry 16 (1), 139-147.

[3] Basthomi, Y. (2006). Rhetorical odyssey and trajectories: a personal reflection. TEFLIN Journal, 17 (2), 99-110.

[4] Basthomi, Y. (2007). Learning from the discursive practice of reviewing and editing: English research article publication in Indonesia. Jurnal Pendidikan dan Pembelajaran, 14 (1), 65-74.

[5] Basthomi, Y. (2009). Examining spaces in doctoral prospectuses. TEFLIN Journal, 20 (2), 140-158.

[6] Baynham, M. (2000). Narrative as evidence in literacy research. Linguistics and Education, 11(2), 99-117.

[7] Becker, A. L. (1996). Beyond translation: essays toward a modern philology. Ann Arbor: The University of Michigan Press.

[8] Belcher, D. and Connor, U (Eds.). (2001). Reflections on multiliterate lives. Clevedon: Multilingual Matters, Ltd.

[9] Berkenkotter, C. and T. N. Huckin. (1995). Genre knowledge in disciplinary communication: cognition/culture/power. Lawrence Erlbaum Associates Publishers.

[10] Denshire, S. (2010). The art of 'writing in' the hospital under-life: auto-ethnographic reflections on subjugated knowledges in everyday practice. Reflective Practice. 11 (4), 529-544.

[11] Fenge, L-A. (2010). Sense and sensibility: making sense of a Professional Doctorate. Reflective Practice. 11 (5), $645-656$.

[12] Fischer, F. and Goblirsch, M. (2006). Biographical structuring: narrating and reconstructing the self in research and professional practice. Narrative Inquiry, 16 (1), 28-36.

[13] Flowerdew, J. (2001). Attitudes of journal editors to nonnative speaker contributions. TESOL Quarterly, 35 (1), $121-150$.

[14] Gimenez, J.C. (2010). Narrative analysis in linguistic research. In L. Litosseliti, Research Methods in Linguistics (pp.198-215). London and New York: Continuum.

[15] Golden, J. L., Berquist, G. F., and Coleman, W. E. (1984). The rhetoric of western thought ( $3^{\text {rd }}$ Edn.). Dubuque: Kendall/Hunt Publishing Company.

[16] Harjanto, I. (1999). English academic writing features by Indonesian learners of English. Unpublished Doctoral Dissertation. Malang: PPS UM.

[17] Hayes, D. (2010). Duty and service: life and career of a Tamil teacher of English in Sri Lanka. TESOL Quarterly, 44 (1), 58-83.

[18] Helsig, S. (2010). Big stories co-constructed: Incorporating micro-analytical interpretative procedures into biographic research. Narrative Inquiry, 20 (2), 274-295.

[19] Kartika, O. R. (1997). A Study on rhetoric by Indonesian and English native writers in the Jakarta Post. Unpublished Master Thesis. Malang: PPS UM.

[20] Knee, A. (1999). An American in Bangkok: reconsidering pedagogical values. ADE Bulletin (Fall 1999): 31-35. Retrieved on 13 November 2005 from http://www.adfl.org/ade/bulletin/n123/123031.htm

[21] Lapadat, J. C. (2004). Autobiographical memories of early language and literacy development. Narrative Inquiry, 14(1), 113140.

[22] Latief, M. A. (1990). Assessment of English writing skills for students of English as a foreign language at the Institute of Teacher Training and Education IKIP MALANG Indonesia. Unpublished Ph.D. Dissertation. Iowa: University of Iowa.

[23] McLeod. J. (2006). Narrative thinking and the emergence of postpsychological therapies. Narrative Inquiry, 16 (1), $201-210$.

[24] Nelson, C. D. (2011). Narratives of classroom life: changing conceptions of knowledge. TESOL Quarterly, 45 (3), $463-485$.

[25] Orbán, G. (1999). Western teachers in Eastern Europe: a student's perspective. ADE Bulletin 123 (Fall 1999): 50-51. Retrieved on 13 November 2005 from http://www.adfl.org/ade/bulletin/N123/123050.htm

[26] Papp, J. (1999). At the meeting of Eastern and Western scholarship. ADE Bulletin 123 (Fall 1999): 52-54. Retrieved on 13 November 2005 from http://www.adfl.org/ade/bulletin/N123/123052.htm

[27] Rogers, J. McL. (2011). Teaching undergraduate researchers to theorize and practice narrative inquiry. Canadian Journal for Studies in Discourse and Writing 23 (1), 1-16.

[28] Schnee, E. (2009). Writing the personal as research. Narrative Inquiry, 19 (1), 35-51.

[29] Swales, J. M. (1990). Genre analysis: English in academic and research settings. Cambridge: Cambridge University Press.

[30] Swales, J. M. (2004). Research genres: explorations and applications. Cambridge: Cambridge University Press.

[31] Tardy, C. M. (2005). "It's like a story": rhetorical knowledge development in advanced academic literacy. Journal of English for Academic Purposes, 4, 325-338.

[32] Underwood, K. (2011). 'Facework as self-heroicisation: a case study of three elderly women.' Journal of Pragmatics 43, 22152242. 
Yazid Basthomi is Lektor at the English Department, Universitas Negeri Malang, Indonesia. His recent publications include 'Competing discourses in thesis advisement: Reflecting on the writing of terms of address in acknowledgements section.' Selected Articles in English Language Teaching. IIEF \& RELO-US. Embassy (2010). 